\title{
How does earnings advantage from tertiary education vary by field of study?
}

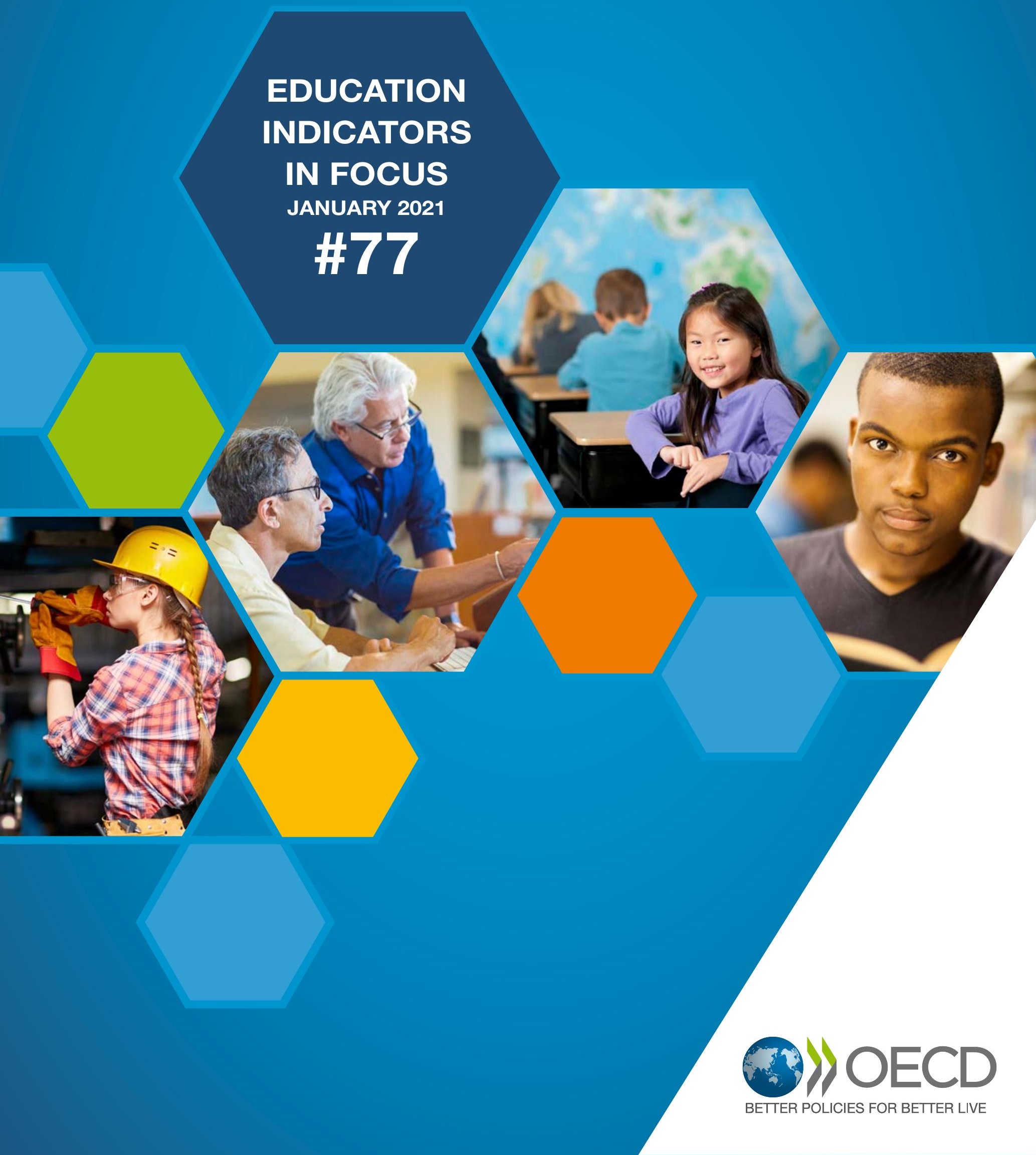


- In all OECD countries, tertiary-educated workers earn more on average than those with only upper secondary education. However, these averages mask important variations between fields of study.

- On average across countries with available data, tertiary-educated workers with a degree in the best-paid field of study (medical and dental health) earn nearly twice as much as those with a degree in the worst-paid field of study (arts and humanities). In one-third of OECD countries with available data, arts and humanities tertiary graduates earn less than those with only upper secondary education.

- The COVID-19 pandemic has highlighted how vital health care and teaching are for society to function as a whole. However, the average earnings of tertiary graduates in some related fields of study, such as nursing, were much lower than most other fields of study in 2017.

- There is no clear correlation between the relative earnings advantage for a field of study and the share of graduates in that field. On average, a far smaller share of recent graduates chose to study information and communication technologies (ICT) than arts and humanities, despite ICT graduates' earnings being about 52\% higher.

On average, adults with a tertiary education earn more than those with only an upper secondary education in all OECD countries..

Over the last decade, tertiary education has expanded in OECD countries (OECD, 2019 ${ }_{[11}$ ). In 2018, the share of tertiary-educated adults reached $39 \%$ on average across OECD countries, up from $29 \%$ in 2008. Given the cost of investing in a tertiary education, a high earnings advantage should be a strong incentive for individuals to pursue a tertiary degree (OECD, $2017_{[2]}$ ). On average across OECD countries, tertiaryeducated adults earn $58 \%$ more than adults who only attained upper secondary education (Figure 1).

The earnings advantage of tertiary education varies substantially across countries, from $22 \%$ in Sweden to $138 \%$ in Chile. In countries with a well-qualified workforce, the wage premium for tertiary-educated workers tends to be lower. Australia and most Nordic countries (Denmark, Finland, Norway and Sweden) have a high share of tertiary-educated workers and a relatively low wage premium for tertiary education over upper secondary (Figure 1). However, the reasons for lower wage premiums differ. In Australia, the situation is partially explained by the good labour-market outcomes of adults with upper secondary vocational qualifications (OECD, 2019 ${ }_{[1]}$ ). Employers actively participate in vocational education in Australia, which ensures students acquire the skills they need for their future occupation (OECD, 2016 ${ }_{[33}$ ). In the Nordic countries, the below-average wage premium is partially related to policies that prioritise inclusion and equality, leading to a narrower income distribution overall (OECD, 2019 ${ }_{[1]}$ ).

In contrast, in Chile, Colombia and Costa Rica, less than $25 \%$ of adults have a tertiary education and tertiary-educated adults have the highest relative earnings across OECD countries (Figure 1). The shortage of qualified workers in these countries might be related to the greater need for private funding to acquire a tertiary degree (OECD, 2017 ${ }_{[4]}$ ). However, high relative earnings may also be associated with the wider distribution of income in these countries.

Cross-country differences in earnings advantage of tertiary education may also reflect differences in labour-market flexibility. In some countries, employers may recognize and may be able to extract more value from the skills developed, even if the degree earned may not match the one commonly expected for a given position (OECD, 2016 $\left.6_{[5]}\right)$.

but the earnings advantage varies widely by field of study and across countries

There are wide discrepancies in the earnings advantage between fields of study. On average across the 15 OECD countries with available data, workers with a tertiary degree in the broad field of arts and humanities earn 17\% more than adults with an upper secondary qualification (in any field), while the wage premium reaches $104 \%$ for those with a qualification in medical and dental health (Figure 2). In other words, tertiary-educated workers with a degree in the best-paid field of study earn nearly twice as much as those with a degree in the worst-paid field of study on average across these 15 OECD countries.

The earnings advantages of different fields of study also differ remarkably across countries. In Chile and the United States, all tertiary fields of study generate higher earnings than an upper secondary 
Figure 1. Share of tertiary-educated adults and relative earnings of tertiary-educated workers (2018) 25-64 year-old workers (full- and part-time workers); upper secondary education $=100$

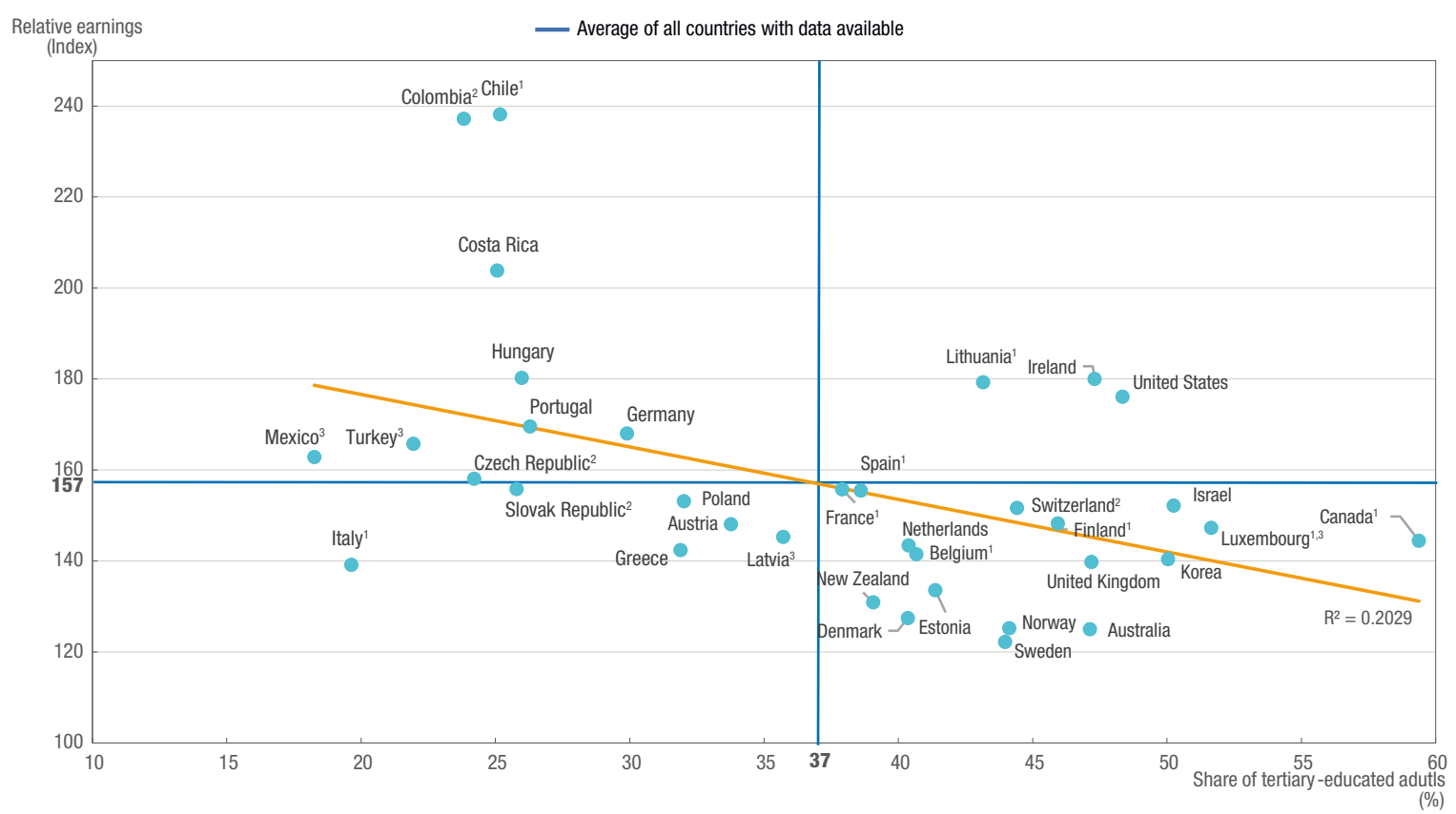

1. Year of reference differs from 2018. Refer to the source table for more details.

2. Index 100 refers to the combined ISCED levels 3 and 4 of the educational attainment levels in the ISCED 2011 classification.

3. Earnings net of income tax.

Source: OECD (2020), Education at a Glance Database, https://stats.oecd.org/.

education. Even workers with a tertiary degree in arts and humanities earn over 50\% more than workers with an upper secondary education (Figure 2). However, in some countries, participation in tertiary education does not necessarily guarantee higher earnings. Some fields of study yield a negligible wage premium or even an earnings disadvantage over an upper secondary education. In Australia, Denmark, Norway, Sweden and the United Kingdom, workers with a tertiary degree in arts and humanities earn less than those who only attained upper secondary education. In the United Kingdom, tertiary-educated workers with a degree in the field of education also earn less than those with only an upper secondary qualification.

Earning differences across fields of study are remarkable even in highly inclusive and equitable countries with lower wage premiums for tertiary education. In Norway, where the average earnings advantage of tertiary education is far below the OECD average, workers with a degree in the highest-paying field (medical and dental) still earn twice as much as those with a degree in the lowest-paying field (arts and humanities). A mismatch between the field studied and the final occupation may result in lower pay. For example, more than $70 \%$ of tertiary-educated adults with a degree in arts and humanities work in another field on average across participating countries to the Survey of Adult Skills (PIAAC). A higher probability of field-of-study mismatch is associated with a larger wage penalty, as these workers are more likely to downgrade when they find work in other fields (Montt, 2015 ${ }_{[6]}$ ).

The global COVID-19 crisis is challenging many countries' health systems and economies and has brought to the fore occupations such as nursing and teaching, which have and continue to play a vital role during the pandemic. However, tertiary graduates from the related fields of study are often poorly paid compared to others. In 2017, their earnings were almost 35\% less than those with a tertiary degree in engineering, manufacturing and construction on average. In Norway, adults with a tertiary degree in nursing and associated health fields barely earn any more than those with only upper secondary education, whereas in Germany they earn 52\% more (Figure 2). 
Figure 2. Relative earnings of tertiary-educated adults, by field of study (2017)

25-64 year-old workers (full- and part-time workers); upper secondary education (all fields) = 100

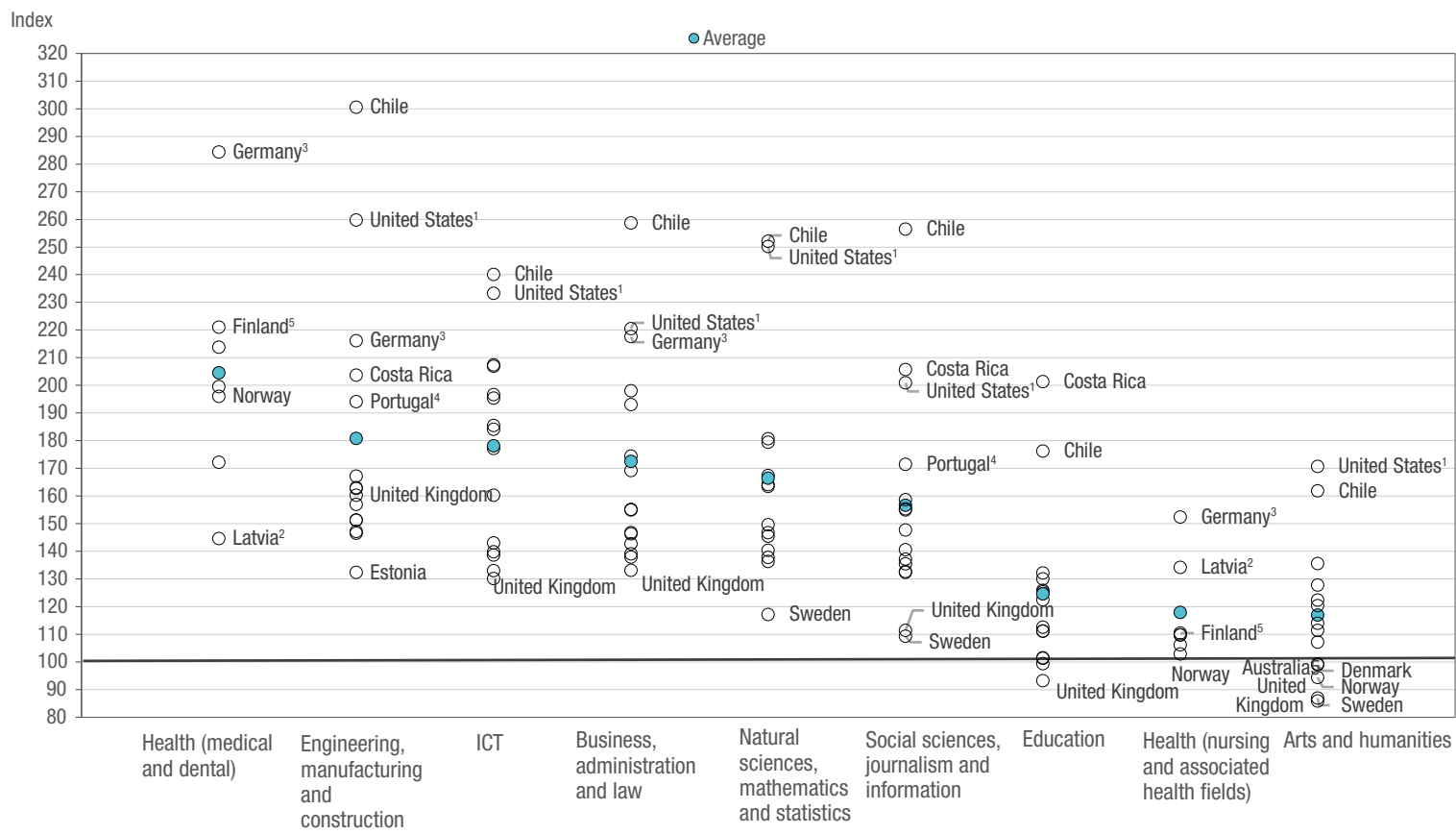

1. Data refer to the field of study at bachelor's level.

2. Earnings net of income tax.

3. Earnings refer to academic programmes only.

4. Arts and humanities does not include the subfield of languages.

5. Year of reference 2016.

Fields of study are ranked in descending order of average relative earnings for the countries with data available.

Source: OECD (2020), Education at a Glance Database, https://stats.oecd.org/.

The popularity of different fields of study does not necessarily reflect their earnings advantage

With participation in tertiary education growing, the important question for today's young people might be their choice of field of study, rather than whether or not to pursue a tertiary qualification. From an economic point of view, the share of those graduating from different fields of study might be expected to align with those fields' relative earnings advantage.

Figure 3 compares the earnings advantage by field of study with the share of those graduating from each field of study in 2017, using the average across the 15 OECD countries with available data. Broad fields of study associated with an above-average earnings advantage, such as business, administration and law and engineering, manufacturing and construction, also tend to have larger share of graduates on average. Meanwhile, arts and humanities, and nursing and associate health fields, which offer below-average earnings advantages, are less popular among tertiary graduates on average across OECD countries with data. However, the share of tertiary students graduating from information and communication technologies (ICT) is $4.3 \%$, less than half the share for arts and humanities (9.7\%), even though adults with an ICT degree earn on average about 52\% more than those with an arts and humanities degree. Although not shown in the figure, the lack of clear correlation between the share of tertiary graduates and relative earnings advantage by field of study is also true for individual countries.

Using higher earnings as a proxy for labour-market demand, the considerable wage premium for certain fields of study suggests an imbalance between supply and demand among skilled workers. With technological progress, labour-market demand for ICT and engineering qualifications should remain strong in the future. However, the share of young adults attaining degrees in these fields of study appears to be stable or even decreasing (OECD, 2019 [1] $)$. On average across OECD countries, the percentage of 25-64 year-olds with a tertiary degree in engineering, manufacturing and construction is $16 \%$, but the share of recent graduates earning a tertiary degree in this field is only $14 \%$.

Many countries have been affected by the shortfall in nurses following the COVID-19 outbreak. In 2017, about $8 \%$ of tertiary graduates on average across OECD countries with data earned a degree in nursing 
Figure 3. Relative earnings of 25-64 year-olds and the share of tertiary students graduating from each field of study (2017)

Average across countries with data available; upper secondary education (all fields) $=100$

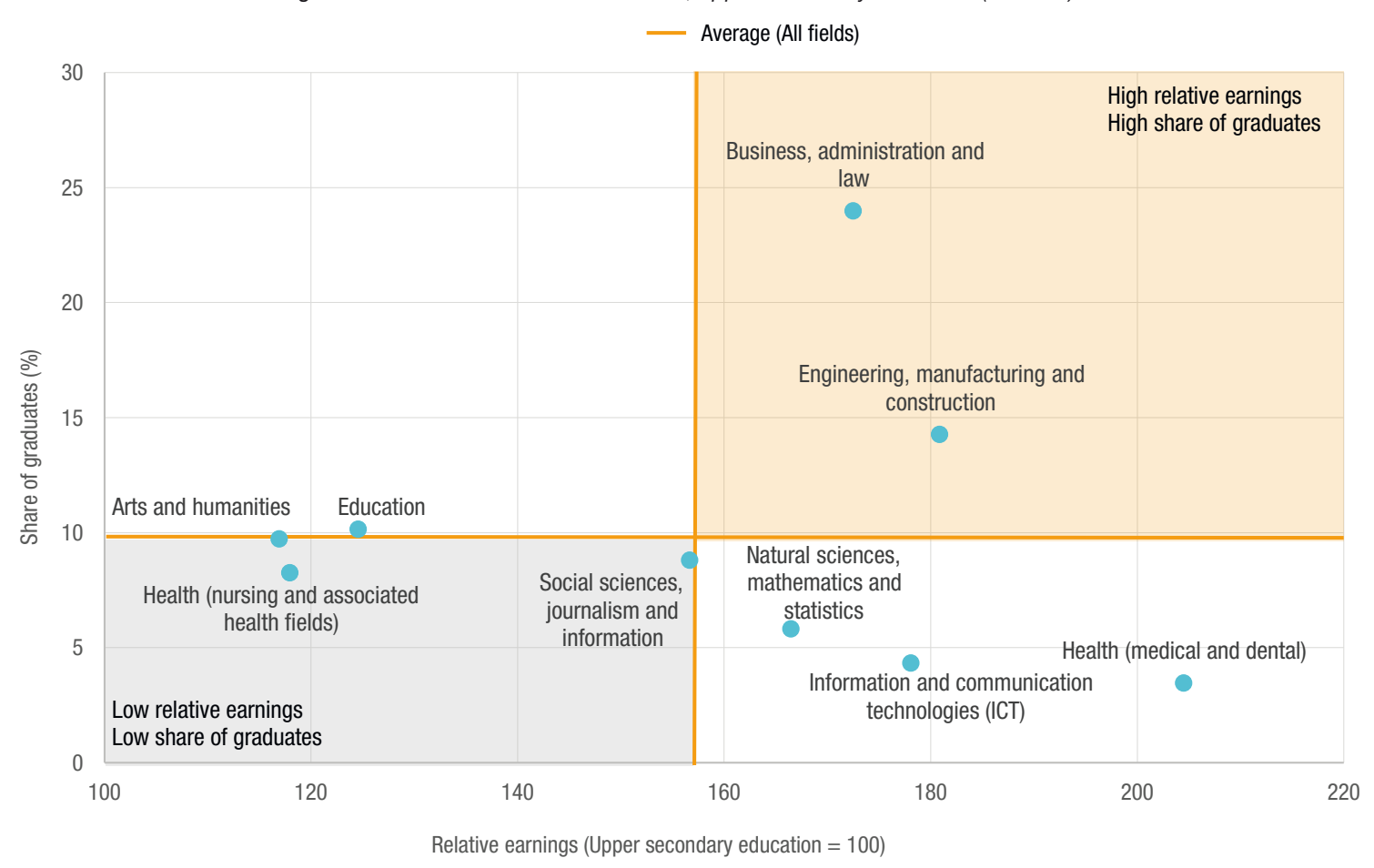

Note: the calculation of the average only takes into account the fields of study shown in the figure.

Source: OECD (2020), Education at a Glance Database, https://stats.oecd.org/.

and associated health fields. This share may fall in the coming years as the profession becomes less attractive to the younger generation. The results from PISA 2018 showed that only 3\% of 15 -year-olds expected to work in nursing and midwifery on average across the OECD. Young people often saw the nursing professions as old fashioned and offering poor career opportunities (OECD, 2020 ${ }_{[7]}$ ). If current earning patterns continue, the very low earnings advantage of nursing and associated health fields could aggravate the shortage of talented nurses, even though these professions have become more highly valued during the COVID-19 pandemic.

The literature on education and labour-market outcomes highlights that at least three factors other than wage effects could influence students' preferences for a field of study. First, some well-paid fields may be highly selective. Students without a strong academic background would not apply or not be accepted in these fields. This is likely to be the case for the broad health and welfare field. For example, in Colombia, Lithuania and Mexico, more than 50\% of applicants are rejected from this field of study., where a remarkable share of applicants are rejected in most countries with available data (OECD, 2019 II1 $_{\text {) }}$ ). Second, students often lack good labour-market information when making their decisions. Experimental studies show that students often estimated earnings wrong in most fields of study (Wiswall and Zafar, $\left.2011_{[8]}\right)$. Upper secondary students may not have reliable information about earning prospects in the labour market, and wrong perceptions of earnings could lead to students being over-represented in the lower-paying fields of study (OECD, $2017_{[2]}$; Barone et al., 2017 ${ }_{[99}$ ). Third, wage premium is only one of the dimensions of the rewards from work. Personal interests and motivations also have an impact on field choice. For instance, students majoring in arts and humanities would probably earn more if they studied a business degree, but they opt for the less lucrative qualification because of their interest in the field and for personal fulfilment (Altonji, Arcidiacono and Maurel, 2016 ${ }_{110}$ ). In addition, personality traits and psychological factors can influence students' field preference. For example, extrovert young people have a higher likelihood of studying business, economics and law, as they may expect more social interactions and/or for being the focus of attention (Humburg, 2017 ${ }_{[11]}$ ).

Monetary incentives alone cannot balance the supply and demand of skills. With the rapid development of technologies, the lack of qualified workers with a degree in ICT may intensify over the next years if current trends continue. The current COVID-19 pandemic has also underscored the importance of 
promoting occupations which form the backbone of society, particularly when those may be less well rewarded in the labour market. Understanding students' choices of what to study is therefore critical for policy makers, as the distribution of tertiary graduates today predicts the composition of skills in the economy tomorrow. Some countries are taking clear steps to tackle the imbalance of supply and demand of skills. Most recently, Australia has adjusted fees for tertiary education to encourage enrolment in the fields of study the Australian economy needs most. For example, students enrolled in arts and humanities now face much higher costs than those in engineering and health (Khadem, $2020_{[12]}$ ).

\section{The bottom line}

A tertiary degree yields better earnings, especially in countries with a small share of tertiaryeducated adults in the population. However, this earnings advantage varies significantly by field of study. In some countries, workers with a tertiary degree in arts and humanities earn less than those with just an upper secondary education. Occupations that have formed the backbone of society during the COVID-19 crisis, such as education and nursing, have among the lowest relative earnings of all fields of study. There is no clear correlation between the share of tertiary graduates by field of study and the relative earnings advantage. This may be due to the selectiveness of some fields, students' personal interests or misinformation about the labour market. Policy makers will need to consider ways beyond market mechanisms to increase the attractiveness of fields of study which offer essential skills for society.

\section{REFERENCES :}

[10] Altonji, J., P. Arcidiacono and A. Maurel (2016), “The analysis of field choice in college and graduate school: Determinants and wage effects", in Handbook of the Economics of Education, Elsevier, http://dx.doi. org/10.1016/b978-0-444-63459-7.00007-5.

[9] Barone, C. et al. (2017), "Gender, information barriers and fields of study choice: A field experiment", LIEPP Working Paper, No. 63, SciencesPo, https://spire.sciencespo.fr/hdl:/2441/6nemhd9te89l1akhtlfqe8589f/ resources/wp63-barone-gender-info-barriers-amp-study-choice.pdf.

[11] Humburg, M. (2017), "Personality and field of study choice in university", Education Economics, pp. 366-378, https://doi.org/10.1080/09645292.2017.1282426.

[12] Khadem, N. (2020), “Government's university fee changes mean humanities students will pay the entire cost of their degrees", ABC News website, https://amp.abc.net.au/article/12374124.

[6] Montt, G. (2015), "The causes and consequences of field-of-study mismatch: An analysis using PIAAC", OECD Social, Employment and Migration Working Papers, No. 167, OECD Publishing, Paris, https://dx.doi. org/10.1787/5jrxm4dhv9r2-en.

[3] OECD (2016), Investing in Youth: Australia, OECD Publishing, Paris, http://dx.doi.org/10.1787/9789264257498en.

[5[ OECD (2016), Skills Matter: Further Results from the Survey of Adult Skills, OECD Skills Studies, OECD Publishing, Paris, https://dx.doi.org/10.1787/9789264258051-en.

[4] OECD (2017), "Educational attainment and investment in education in Ibero-American countries", Education Indicators in Focus, No. 50, OECD Publishing, Paris, https://dx.doi.org/10.1787/48a205fb-en.

[2] OECD (2017), State of Higher Education 2015-16, OECD Higher Education Programme (IMHE), OECD, Paris, https://www.oecd.org/education/imhe/the-state-of-higher-education-201516.htm.

[1] OECD (2019), Education at a Glance 2019: OECD Indicators, OECD Publishing, Paris, https://doi.org/10.1787/ f8d7880d-en.

[7] OECD (2020), "Can nursing thrive in the age of the coronavirus? What young people think about the profession”, OECD Forum Network website, https:/www.oecd-forum.org/posts/can-nursing-thrive-inthe-age-of-the-coronavirus-what-young-people-think-about-the-profession-dce5a659-cc6d-4914-b41242e994be8197.

[8] Wiswall, M. and B. Zafar (2011), "Determinants of college major choice: Identification using an information experiment", Staff Report, No. 500, Federal Reserve Bank of New York, http://hdl.handle.net/10419/60833. 
PISA in Focus

Teaching in Focus

What are the roles and salaries of school heads?.

\section{CONTACT:}

Yanjun Guo (Yanjun.GUO@oecd.org)

Photo credit: @ Christopher Futcher / iStock; @ Marc Romanelli / Gettyimages; @ michaeljung / Shutterstock; @ Pressmaster / Shutterstock

This work is published under the responsibility of the Secretary-General of the OECD. The opinions expressed and arguments employed herein do not necessarily reflect the official views of OECD member countries.

This document, as well as any data and any map included herein, are without prejudice to the status of or sovereignty over any territory, to the delimitation of international frontiers and boundaries and to the name of any territory, city or area.

The statistical data for Israel are supplied by and are under the responsibility of the relevant Israeli authorities. The use of such data by the OECD is without prejudice to the status of the Golan Heights, East Jerusalem and Israeli settlements in the West Bank under the terms of international law. 